\title{
AUTONOMIA PARKATÊJÊ PARA PRESERVAR SUA LÍNGUA NATIVA: ME IKWY TEKJÊ RI*
}

\author{
Maria de Nazaré Moraes da Silva ${ }^{1}$ \\ Marília de Nazaré Ferreira-Silva ${ }^{1}$ \\ Walkyria Passos Magno e Silva ${ }^{1}$
}

\begin{abstract}
RESUMO: A partir da Constituição de 1988, o ensino formal no Brasil passou por modificaçóes e, hoje em dia, as escolas buscam adequar suas ações ao atual paradigma educacional. As comunidades indígenas demarcam lugar nessa discussão, a exemplo dos Parkatêjê, habitantes da Reserva Mãe Maria, no Pará. O presente artigo caracteriza-se como uma pesquisa bibliográfica que reúne informaçóes acerca da iniciativa desse povo para preservar a sua cultura. Também levanta dados sobre a implantação do ensino formal no país e sobre a autonomia, um fenômeno relacionado às práticas pedagógicas contemporâneas. Destaca-se que a Educação Escolar Indígena (EEI) ainda se mostra embrionária em relação à preservação de línguas nativas, por isso a necessidade de estudos etnográficos em escolas indígenas. Por fim, o artigo ressalta a importância de divulgação da experiência Parkatêjê sobre a validação de sua própria cultura.
\end{abstract}

Palavras-chave: Autonomia. Educação escolar indígena. Povo Parkatêjê.

\section{PARKATÊJÊ AUTONOMY TO HELP PRESERVE THEIR NATIVE LANGUAGE: ME IKWY TEKJÊ RI}

ABSTRACT: After the 1988 Constitution, formal education in Brazil suffered many changes. Nowadays, schools tend to adapt their actions to the current educational paradigm, and indigenous communities take a stand in this matter. One said community is the Parkatêjê, inhabitants of the Mãe Maria Reservation Area, in Pará. This paper, based on published materials, gathers information about the initiative of this community to preserve its culture. It also brings data about the implementation of formal education among indigenous people and about autonomy, a phenomenon related to current pedagogical practices. This text highlights the fact that

\footnotetext{
*Este artigo é um recorte do projeto de pesquisa de doutorado em andamento de Maria de Nazaré Moraes da Silva, intitulado Parkatêjê Lingua de Herança: minha lingua ensinada do jeito que eu quero, submetido ao Programa de Pós-Graduação do Instituto de Letras e Comunicação da UFPA, linha de pesquisa "Análise, descrição e documentação das línguas naturais". ${ }^{1}$ Universidade Federal do Pará - Belém (PA), Brasil. E-mails: mn@ufpa.br, marilia@ufpa.br, walkyriamagno@gmail.com
} DOI: 10.1590/ES0101-73302016125693 
Indigenous Education has not yet matured with regards to the preservation of native languages and suggests that ethnographical studies should be carried out in indigenous schools. The text also aims at helping to spread the word about the Parkatêjê experience in valuing its own culture.

Keywords: Autonomy. Indigenous schooling. Parkatêjê people.

\section{L'AUTONOMIE PARKatêJÊ POUR PRÉSERVER SA LANGUE AUTOCHTONE : ME IKWY TEKJÊ RI}

Résumé : Depuis la Constitution de 1988, l'enseignement formel au Brésil a fait face à des changements et, de nos jours, les écoles cherchent à adapter leurs actions au paradigme éducationnel actuel. Les communautés indigènes prennent place autour de cette discussion, à l'exemple du peuple Parkatêjê, établi dans la réserve indigène Mãe Maria, dans l'État du Pará. Cet article se caractérise par un travail de recherche bibliographique qui rassemble des informations sur l'intervention de ce peuple afin de préserver sa culture, bien que sur la mise en ouvre de l'éducation formelle dans le pays ainsi que sur l'autonomie, signalé comme un phénomène lié aux pratiques pédagogiques contemporaines. Il fait remarquer que l'Éducation formelle indigène est encore rudimentaire par rapport à la préservation des langues autochtones, et suggère des études ethnographiques dans les écoles indigènes. Enfin, il souligne l'importance de la diffusion de l'expérience Parkatêjê pour la validation de sa propre culture.

Mots-clés : Autonomie. Éducation formelle indigène. Peuple Parkatêjê.

\section{Introdução}

A

questão indígena no Brasil sempre esteve sob a responsabilidade de um Estado regulador. De início, a imagem do índio vinculou-se a um ser primitivo e incapaz de exercer a sua autonomia. Em consequência, a educação formal direcionada aos povos indígenas por muito tempo desconsiderou suas peculiaridades, pautando-se, assim, em um paradigma homogeneizador.

Essa forma de proceder persistiu até os anos 1980, quando o Brasil passou a experimentar modificaçóes em sua estrutura interna. Nessa época, reivindicaçóes organizadas pela sociedade brasileira, envolvendo, dentre outras, questóes étnicas, foram decisivas para que as comunidades indígenas conquistassem espaço para atuar como protagonistas de seu destino no debate político e acadêmico. Vale acrescentar que as açóes pedagógicas mostraram-se fundamentais no diálogo entre lideranças indígenas e a sociedade majoritária, culminando com a promulgação da Constituição de 1988, a partir da qual as práticas educacionais seguiram novos rumos. 
No momento contemporâneo, a escola apresenta-se como um espaço decisivo para a emancipação econômica e política dos povos indígenas. $\mathrm{O}$ desafio maior tem sido garantir um ensino significativo, reflexivo e fomentador de autonomia, adaptado às diferenças socioculturais. Entende-se que, para isso, o foco deve ser a determinação de objetivos e estratégias por parte da comunidade em geral, mas também da atitude de cada um de seus integrantes no papel de aprendentes.

No âmbito dessa discussão, o presente artigo apresenta um projeto de amplo escopo que comprova a atitude e a organização dos Parkatêjê na luta pela sobrevivência de seu maior patrimônio: a sua cultura. Esses indígenas, falantes da língua de mesma denominação que pertence ao tronco linguístico Macro-jê (RODRIGUES, 1986), habitam a Reserva Indígena Mãe Maria, no município Bom Jesus do Tocantins, em Marabá, no sudeste do Pará. Antes, porém, há uma seção constituída por informaçôes acerca do histórico da educação formal no país. $\mathrm{Na}$ seção seguinte, apresenta-se uma nova perspectiva educacional com base nos postulados da autonomia, teoria segundo a qual é tarefa da instituição escolar propiciar condiçóes para que os próprios aprendentes se tornem agentes de seus projetos. Ao final, adentra-se o universo Parkatêjê por meio de sua história, narrada pelo líder tradicional.

\section{A propósito da educação escolar indígena no Brasil}

Antes de os portugueses aportarem na terra que, hoje, chama-se Brasil, o país era habitado por povos com profundo conhecimento da natureza, dotados de costumes e crenças nunca antes vistos pelo colonizador ${ }^{1}$. Desde os primeiros encontros entre europeus e indígenas, que não ocorreram de forma totalmente pacífica, estabeleceu-se uma relação pautada por diferentes intenções. De um lado, índios curiosos, interessados em produtos exóticos; de outro, europeus decididos a se beneficiar da riqueza do território "descoberto", impondo sua língua, cultura e costumes.

Com a chegada dos missionários jesuítas no século XVI, iniciou-se o processo de catequização e batismo dos gentios ${ }^{2}$, o que facilitou a intenção dos colonizadores no sentido de explorá-los e escravizá-los. Muitos indígenas adequaram-se a esse plano, com exceção daqueles que causavam temor aos portugueses, como os líderes e os pajés.

Como os colonizadores precisavam garantir domínio, suas preocupações imediatas, por volta dos séculos XVI e XVII, consistiam em impor a língua portuguesa e em proibir a interação dos membros das comunidades indígenas em suas línguas tradicionais. Em outras palavras, "aprisioná-los ao mundo e à cultura do branco, retirando-lhes a autonomia” (PAIVA; VIEIRA, 2005, p. 1).

Essa educação monopolizadora e culturalmente invasiva perdurou por muito tempo, mas não impediu que os indígenas cultivassem entre si um processo 
de resistência e oposição ao longo da história. Dessa forma, continuaram lutando para reaver sua identidade, o que culminou em sua conquista de espaço na Constituiçáo Brasileira de 1988. Somente a partir de entáo lhes foi assegurada, entre outros direitos, a educação formal bilíngue e intercultural, específica e diferenciada (BRASIL, 1996), e suas necessidades foram expressas em capítulo destinado à Educação Escolar Indígena (EEI) no Plano Nacional de Educação (PNE), fixado pela Lei 10.172/2001 (BRASIL, 2004).

Segundo Cohn (2014), a política cultural da EEI passou a constituir-se, ao mesmo tempo, como uma política do Estado, por ser regulamentada segundo a Constituição, e como uma política indígena amplamente difundida - tanto quanto o é o direito a terras - por meio da qual as comunidades indígenas buscam assegurar o ensino formal, em todos os níveis, a seus integrantes. A autora sublinha que

[...] a implantação e a formulação da escola em terras indígenas e para um público indígena têm impactos econômicos - geração de renda e criação de postos de trabalho -, políticos - aspecto crucial da chefia e da liderança indígena atual, pautada na agenda dos direitos indígenas em nível nacional, debate sobre a representatividade em mecanismos de controle social, cargos no estado - mas, também, culturais (COHN, 2014, p. 314).

Em meio ao crescente debate em favor da educaçáo e da diversidade linguístico-cultural do país, em especial no que diz respeito aos povos indígenas, algumas questóes precisam ser investigadas, por exemplo: realidade sociolinguística; especificidades culturais; e políticas linguísticas internas.

DeacordocomD’Angelis (2014), épossível queo Brasiljátenha perdido pelo menos mil línguas indígenas desde a fase de colonização até os dias atuais. A quantidade de línguas ainda existente é inferior a 160, as quais contam com menos de 500 falantes. O autor observa "que mais de 40 línguas (isto é, mais de $25 \%$ das línguas indígenas vivas no Brasil) contam com menos de 100 falantes cada uma e, dessas, quase 30 contam menos de 20 falantes cada" (D’ANGELIS, 2014, p. 94).

Com base nesse diagnóstico, introduz-se a primeira questão: a realidade sociolinguística. Conforme D’Angelis (2014), tal assunto abrange aspectos como: a relação entre número de falantes nativos de determinada língua; faixa etária; sexo dos falantes; práticas de leitura e escrita; contextos sociais e usos linguísticos. Em seu ponto de vista, "se a metade da populaçấo que não fala a língua for constituída da parte mais jovem da comunidade [...] nesse caso a língua está seriamente ameaçada e, seguramente, doente" (D’ANGELIS, 2014, p. 98).

A situação dos Parkatêjê corresponde a esse caso, motivo pelo qual sua língua requer atenção. A comunidade é constituída de, aproximadamente, 478 pessoas (JÓPAIPARE, 2011b), um total que inclui também não indígenas, em conse- 
quência de unióes conjugais. Segundo Ferreira (2003), a fluência na língua nativa é observada somente entre índios da primeira geração; a segunda geração interage principalmente por meio da língua portuguesa; a comunicaçáo das crianças é feita somente por meio da língua portuguesa, porém elas conhecem algumas palavras que lhes foram ensinadas na escola ou pelos índios mais velhos ${ }^{3}$.

Por outro lado, é crescente o interesse desse povo em buscar meios para revitalizar a língua tradicional, ainda funcional naquele lugar. Isso se observa em atividades tradicionais nas quais a parkatêjê continua a se fazer presente, no esforço dos professores indígenas em inseri-la na escola, no empenho dos velhos para repassar aos jovens e às crianças as narrativas orais (como textos míticos, fábulas, canções, entre outras), bem como no envolvimento de todos em empreendimentos cujo intuito é resguardar a língua aos seus descendentes - a exemplo do projeto que será apresentado na última seção do artigo.

Acerca do assunto em questão, concorda-se com Bomfim e Costa (2014) no que diz respeito ao sentido de revitalizar uma língua. Para os autores,

[...] revitalizar não é sinônimo de voltar a falar uma língua, mas de reconhecer a função de uma língua em uma comunidade. Função que independe da fala, tornando-se essa apenas uma das funções possíveis. A revitalização contribui para mostrar que língua não é sinônimo de uso para a comunicação, essa premissa já não é única há muito. Neste processo de busca da língua indígena, a comunicaçáo ganha novos aspectos, inclusive identitários, para mostrar que comunicar, conversar, aparecer, convencer, fortalecer, são apenas alguns itens [...] (BOMFIM; COSTA, 2014, p. 19).

O histórico da educaçáo formal entre os Parkatêjê data de 1976. De início, esteve sob a responsabilidade da Fundação Nacional do Índio (Funai); no ano de 1989, passou à Secretaria de Estado de Educaçáo (SEDUC), considerada responsável pela primeira experiência com povos indígenas no estado do Pará (ARAÚJO, 1996). Diante de um percurso de muitas tentativas, esse projeto escolar foi aceito em definitivo a partir do momento em que se estabeleceu um diálogo entre os regimes tradicionais de conhecimentos e a escola; ou seja, quando especificidades culturais dos Parkatêjê foram atendidas.

Santos (1994) informa que cada sociedade é movida por dinâmicas, crenças e lógicas internas peculiares. Sendo assim, a cultura de determinado povo o fará único entre os demais, pois somente sua história pode explicar "as maneiras como seus setores, suas concepçôes, formas, produtos, técnicas, instituições se relacionam, formando uma teia que condiciona seu próprio desenvolvimento" (SANTOS, 1994, p. 76), e isso precisa ser considerado na EEI.

Ainda acerca de especificidades culturais, Cohn (2014, p. 316) sugere uma análise etnográfica em escolas indígenas para mais esclarecimentos em 
relação ao que pode parecer estranho aos olhos não indígenas, e ressalta que "só vendo a cultura em sala de aula que podemos entender como - e se, e por que - esta escola é específica”.

$\mathrm{Na}$ cultura Parkatêjê, por exemplo, "nada é feito de forma isolada" (ARAÚJO, 1996, p. 294) ou, como dizem Laraia e Da Matta (1978, p. 164) ao se referirem ao dualismo Jê-Timbira, "cada parte é pensada sempre com relação à outra”, sendo tais princípios adotados no ensino formal. Alunos com conhecimento mais aprofundado sobre determinado assunto costumam auxiliar os demais, embora não estudem na mesma sala de aula, diferentemente do que ocorre em escolas náo indígenas. Acrescente-se a isso que o respeito ao ritmo das atividades tradicionais é considerado no calendário letivo.

Em relação às políticas linguísticas internas, de início cabe citar o Estado Colonial e a Igreja, instâncias de poder que interferiram em grande medida no destino das línguas indígenas brasileiras, tanto com relação ao seu uso, quanto no que diz respeito ao estabelecimento de normas gramaticais, à produção de material escrito e ao desenvolvimento de metodologias de ensino. Esse modo de proceder foi reforçado por paradigmas pedagógicos vivenciados no país, principalmente antes da aludida Constituição. Freire (2014, p. 375) relembra que "enquanto no período colonial a catequese funcionou como instrumento de reprodução da língua geral e da força de trabalho, no Império e na República papel equivalente em relação à língua portuguesa foi desempenhado pela escola”.

O primeiro modelo de educação nas comunidades indígenas adotado no Brasil foi o assistencialista, que vigorou no período de 1540 a 1910 (um dos mais longos) e teve o propósito de integrar os indígenas à comunidade nacional e retirar de cena suas línguas e tradiçóes (MAHER, 2006; FREIRE, 2014). O segundo modelo, que adotou o paradigma de transição, fez-se presente até por volta de 1970. Neste, a criança indígena, inicialmente monolíngue (L1), vivenciava o bilinguismo de transição, na sua língua nativa (L1) e na língua portuguesa (L2), e depois se tornava monolíngue na língua portuguesa (L2). Assim, a L2, depois de assimilada, passava a prevalecer como língua de instrução, e a língua indígena, gradativamente, era suprimida da escola (MAHER, 2006).

No momento contemporâneo, o paradigma de transição cede espaço para o paradigma emancipatório, que se fortaleceu com a promulgação da Carta Magna. Destarte, a EEI encontra-se regulada pelo modelo de enriquecimento cultural e linguístico - ou bilinguismo identitário, como informa Freire (2014) - e prescreve alfabetização em língua materna, com a qual também se deve conduzir o ensino nas séries iniciais. Maher (2006, p. 22) acrescenta que, atualmente, "pretende-se que o aluno indígena adicione a língua portuguesa ao seu repertório linguístico, mas pretende-se também que ele se torne cada vez mais proficiente na língua de seus ancestrais". 
Evidentemente, para fazer valer seus direitos é necessário que cada povo aprenda a reconhecer suas necessidades e busque conhecimentos para interferir com propriedade nas discussões de seus Projetos Políticos Pedagógicos (PPP). Quanto a isso, infere-se que os Parkatêjê estejam no caminho adequado; até porque, alguns de seus membros pertencem ao quadro docente de sua escola, e outros já despertaram para a importância de uma qualificação em instituiçôes de ensino superior.

Em linhas gerais, os documentos conquistados nos anos subsequentes à Constituição de $1988^{4}$ e o apoio de organizações não governamentais preveem uma relação mais harmoniosa entre os atores envolvidos na EEI. Por meio de um trabalho conjunto entre povos indígenas e a sociedade não indígena, o enfoque é a implantaçấo de um ensino que evidencie os valores indígenas e que auxilie esses povos na superação das imposiçóes dos tempos coloniais. Esse modo de proceder vem ao encontro das atuais práticas na educação formal do Brasil, conforme evidencia a discussão na seção seguinte.

\section{Uma nova relação educacional sob os princípios da autonomia}

No novo paradigma pedagógico brasileiro, a sala de aula não é mais o único lugar onde o aluno adquire conhecimentos, tampouco é um espaço em que o ensino realiza-se de maneira unilateral. Professor e aluno são coaprendizes, estando ambos comprometidos em dividir responsabilidades na aprendizagem. Nesse contexto, motivação e autonomia são conceitos presentes nas reflexões de vários teóricos, entre os quais Benson (2001), Dantas, Magno e Silva (2006), Dörnyei (2011), e Freire (2011).

Mesmo não atuando como mestre do saber, ao professor cabe o papel de protagonista no fomento da autonomia, principalmente nos primeiros contatos com seus alunos. Nessa fase, o interessante é quando,

[...] no lugar de trazer planos prontos de curso, de unidade e de aula, ele [o professor] traz 'possibilidades'. Essas possibilidades de aula irão acomodar os interesses e as necessidades de seus alunos. Para que isso ocorra, é preciso que ele ouça e interprete seus alunos, procurando estabelecer as conexóes entre os conteúdos do curso e as vidas de seus alunos (DANTAS; MAGNO E SILVA, 2006, p. 145).

Esse diagnóstico inicial é imprescindível para que o professor conheça o grupo heterogêneo com o qual interagirá ao longo do período letivo. Somente após os ajustes de conteúdos, a aprendizagem poderá contemplar grande parcela de alunos. Todavia, dada a complexidade do contexto educacional, náo se pode assegurar a totalidade do sucesso da aprendizagem, pois dificilmente haverá uma turma em que todos os alunos encontrem-se disponíveis ao aprendizado. Segundo Paiva (2005, p. 26), "há 
um conjunto imprevisível de comportamentos dinâmicos possíveis no contexto da aprendizagem [...]".

O fenômeno da autonomia é melhor exercido pelo professor que demonstra comportamento autônomo. Assim, esse profissional estará apto a impulsionar e a assegurar a motivação em seus alunos, apoiando-os nos desafios, disponibilizando-se para negociar atividades, apresentando-lhes mais oportunidades de aprendizagem. A preocupação central deve ser oferecer conteúdos que os preparem para atuar em qualquer circunstância de sua vida.

Dörnyei (2011, p. 208) define motivação como

[...] um estado de alerta cumulativo dinamicamente mutante em um indivíduo que começa, direciona, coordena, amplifica, termina e avalia os processos cognitivos e motores por meio dos quais vontades e desejos iniciais são selecionados, priorizados, operacionalizados e desempenhados (com ou sem sucesso).

O modelo processual de motivação proposto pelo autor divide-se em três fases: pré-acional, acional e pós-acional. Tendo em vista o escopo do presente artigo, discorrer-se-á apenas sobre a fase acional, a qual envolve os seguintes processos básicos: geração e implementação de subtarefas; um processo complexo e contínuo de avaliação; e a aplicação de uma variedade de mecanismos de controle da ação.

A geração e a implementação de subtarefas relaciona-se à aprendizagem em si. Nesse processo, o indivíduo gera (ou recebe) novas subtarefas e novos subprojetos durante o desenrolar da ação. No segundo processo, ocorre a avaliação dos estímulos oriundos do ambiente e o progresso realizado em direção ao resultado da ação, no qual são comparados eventos reais com os previstos ou com aqueles que uma sequência alternativa de açóes poderia oferecer. No último processo, os mecanismos de controle da ação estariam estreitamente relacionados ao processo de avaliação e envolveriam mecanismos autorreguladores para fomentar, apoiar, proteger ou "salvar" a ação de aprender.

Dörnyei (2011) acrescenta que

[...] em atividades de longo prazo, sustentadas ao longo do tempo [...], a motivação não permanece constante, mas é caracterizada por (re)avaliaçóes regulares e equilíbrio entre várias influências internas e externas às quais o indivíduo é exposto, resultando em um padrão relativamente flutuante de esforço e comprometimento (DÖRNYEI, 2011, p. 208).

Por outro lado, o ensino-aprendizagem em ambiente motivador e fomentador de autonomia implica compartilhamento de responsabilidades. Dessa forma, cabe ao aluno exercer controle sobre sua aprendizagem, uma postura possível de 
ser ensinada pelo professor (DANTAS; MAGNO; SILVA, 2006). Observam-se ações autônomas em aprendizes que buscam novos conhecimentos, estabelecem metas particulares, impulsionam-se diante das dificuldades, promovem autoavaliação diante de seu aprendizado, entre outras atitudes.

Benson (2001) insiste que parte do fomento da autonomia provém da negociação instaurada com os aprendentes em torno do que será tratado. Ao assumirem a corresponsabilidade pelo processo de aprendizagem, eles envolvem-se e empenham-se mais para o seu sucesso. $\mathrm{O}$ autor acrescenta que autonomizar-se significa assumir o controle sobre três dimensóes: os processos cognitivos; o gerenciamento da aprendizagem; e o conteúdo a ser aprendido.

Em relação aos Parkatêjê, a forma como o ensino-aprendizagem foi negociado na escola pode ser citada como exemplo nessa discussão. E, como se verá mais adiante, isso também ocorreu quando a comunidade tomou para si a tarefa de registrar a sua história tal como a via, usando seus recursos cognitivos e fazendo esse registro da maneira que queria.

Barbot e Camatarri (1999) comentam que a autonomia não se restringe à sala de aula, pois pode ocorrer em qualquer ambiente de aprendizagem; não é uma capacidade inata, mas possível de ser construída por meio de várias experiências e de atitudes colaborativas entre os membros de cada comunidade. Ademais, pode ser

[...] apresentada tanto como fim do processo de formação e como valor, e inserida em uma sequência de valores gerais ("inserção social", "desenvolvimento pessoal", "compartilhamento de valores comuns", transmissão de patrimônio cultural”). Além disso, reconhece-se forçosamente que esse fim corresponde não somente a um saber, como também a um saber-fazer, a um método que interiorizado de maneira pertinente, permite que se "aprenda por si mesmo” (BARBOT; CAMATARRI, 1999, p. 8).

A definição desses teóricos contempla a formação do aluno dentro e fora da escola. Assim, a aprendizagem é interpretada em sentido amplo, no qual se acrescenta a formação de valores, e se propóe conduzir o aprendente a refletir acerca de seus conhecimentos, a ressignificar conteúdos de forma adequada e segura, de acordo com as situaçóes que se apresentem.

Conforme referido, essa discussão contempla as peculiaridades do Brasil, em especial dos povos indígenas, motivo pelo qual se enfatiza uma educação formal que garanta o acesso ao conhecimento não somente aos falantes da língua majoritária, mas também às minorias linguísticas do território brasileiro 5 . Paiva e Vieira (2005, p. 2) afirmam que "é através da língua que se conhecem a cultura, a religiấo, os costumes e muito da identidade de uma naçáo". 
No que concerne ao contexto indígena, açóes educacionais em prol da autonomia precisam ter à frente seus representantes por serem eles os principais conhecedores das singularidades de suas comunidades. Entre as providências necessárias, Silva (2011, p. 9) destaca: "elaboração de material didático bilíngue; calendário escolar específico; proposta curricular que contemple metodologias específicas, sistemática de avaliação, escolha de conteúdos e programas de formação de professores”.

A escola indígena distancia-se, gradativamente, da visão centralizadora de outrora, e as práticas pedagógicas buscam inserir-se num movimento dialético, tal como propóe Freire (2011), no qual é dado espaço para que o ensino esteja relacionado à língua, à cultura, à história do sujeito aprendente, sustentando, desta forma, a manutenção de sua alteridade sociocultural. Assim entendido, o modelo educacional contemporâneo privilegia a autoafirmação da identidade indígena e vai ao encontro das mencionadas premissas da aprendizagem autonomizadora.

No Brasil, comunidades indígenas demarcam lugar nesse debate e revelam-se autoras de sua própria história, mostrando-se cada vez mais conscientes da importância da EEI como um instrumento político e de transformação social. Os Parkatêjê figuram entre os exemplos dessa realidade. Em 2011, seu líder tradicional desenvolveu uma ação inusitada a fim de estimular a valorização de sua língua e de sua cultura, por meio da qual assumiu o controle sobre o conteúdo da aprendizagem do seu povo. Essa experiência será apresentada a seguir.

\section{Refazendo a história}

Os Parkatêjê são constituídos por remanescentes dos Róhôkatêjê, Akrãtikatêjê e Kỳikatêjê, povos indígenas que decidiram unir-se em uma mesma comunidade quando sua sobrevivência física e cultural parecia ameaçada (FERRAZ, 1984). Seu reduzido número de habitantes (aproximadamente 478 pessoas) é resultado de óbitos decorrentes de doenças e de conflitos travados entre povos indígenas e entre estes e os não índios - conflitos cuja causa principal é a disputa por posse de terras (JÓPAIPARE, 2011b).

O líder tradicional, Toprãmre Krôhôkrenhữm Jópaipaire, é também conhecido como Capitáo ${ }^{6}$. Nascido na antiga aldeia grande Pamrexa ${ }^{7}$, localizada na cabeceira do rio Capim, no Pará, Krôhôkrenhữm cresceu participando de jogos de flechas e empenhando-se para ser um grande caçador, em tudo demonstrando espírito de liderança. Conforme o avançar da idade, sua preocupação tem sido contribuir para a reafirmação da identidade de sua comunidade.

O Capitão relaciona-se com o seu povo como um líder por essência, o que é evidenciado em sua maneira comunicativa, simples e acessível de agir. Atento aos tempos modernos que já adentram a aldeia, aconselha sempre aos mais 
jovens que "[...] o tempo que nós vivemos é outro [...] não pode pensar em si, tem que pensar em conjunto" (JÓPAIPARE, 2011b, p. 150).

$\mathrm{Na}$ aldeia coexistem dois sistemas linguísticos: a língua portuguesa, falada pela maioria das pessoas, e a língua parkatêjê, dominada apenas pelos mais velhos, conforme mencionado. $\mathrm{O}$ enfraquecimento da língua nativa está relacionado tanto ao modo como o ensino formal foi conduzido no Brasil (assunto explanado anteriormente) quanto à época em que projetos de alto impacto ambiental invadiram o território e facilitaram o acesso da comunidade a aspectos cultuais da sociedade ocidental, além de terem contribuído para a destruição dos castanhais, então a principal fonte de renda da aldeia. Araújo (2008, p. 5) informa que

[...] nos anos 80 [...] a televisão passou a estar presente na aldeia. As crianças sentadas no chão em frente ao aparelho, os velhos mais longe, sentados em velhas toras, o chefe e um ou outro em cadeiras, mulheres em esteiras, ficavam fascinados com esse novo "contador de histórias". Era forte instrumento de introdução da língua portuguesa.

Os prejuízos socioculturais advindos do contato com a cultura não indígena são reconhecidos pelos Parkatêjê. Eles estão cientes da importância política e ideológica de se tornarem fluentes na sua língua tradicional e na língua portuguesa, um direito previsto pelo paradigma de enriquecimento linguístico-cultural da EEI. Existem, na comunidade, movimentos em busca de uma escola com currículo cada vez mais adequado às suas especificidades. Em vista disso, a capacitação linguística para facilitar a comunicaçáo com náo índios, bem como a garantia da continuidade da aprendizagem de sua língua nativa, constituem seus objetivos mais prementes.

Comprometido com o seu povo, Krôhôkrenhữm procura transmitir conhecimentos por meio de suas próprias atitudes. Por muito tempo, idealizou registrar suas memórias. Em 2011, esse sonho tornou-se realidade em livro e em vídeo, uma experiência vivenciada pela primeira vez por uma comunidade indígena brasileira.

O empreendimento contou com o auxílio de profissionais de diversas áreas $^{8}$ e de defensores da causa indígena. Contou também, principalmente, com o empenho dos jovens da aldeia, os quais muito se dedicaram ao desafio. O principal objetivo era promover uma mudança significativa nos costumes atuais da comunidade quanto à (re)valorização de sua língua e de sua cultura. Como incentivar os jovens a aprender com os mais velhos?

Por meio do projeto, foram realizadas quatro oficinas com as linguistas que compunham a equipe executora. De modo geral, as oficinas tinham como meta instrumentalizar os jovens para o trabalho, os quais ficaram responsáveis pelas entrevistas com os mais velhos. Após as gravaçôes, eles providenciaram a transcrição dos textos em língua portuguesa. Durante as oficinas, também apren- 
deram a organizar os textos, a digitá-los e a confeccionar desenhos ilustrativos. Em oficina específica, organizaram as fotos de que dispunham no acervo da comunidade, bem como aprenderam a manejar equipamentos e a participar das filmagens.

As fases foram previamente negociadas entre os jovens e o Capitão, sendo orientadas pelos profissionais de cada área. A participação de todos configurou-se como condição imprescindível para a realização do trabalho, que deveria nascer pelas mãos dos próprios indígenas, conforme o desejo de Krôhôkrenhữm. Aqui se vê a importância da negociação e da corresponsabilidade no êxito do projeto. Como foi mencionado, experiências autonomizadoras ocorrem quando envolvem temas significativos para todos os participantes de um projeto.

A comunidade esteve engajada desde as primeiras decisóes, empenhando-se ativamente em todas as etapas. Com o propósito de proteger a motivaçáo entre os participantes diante de tamanho desafio, de modo que os jovens sentissem-se seguros e não desistissem da proposta (DÖRNYEI, 2011), o Capitão ofereceu direcionamento e condiçóes adequados.

As palavras de Dörnyei (2011) acerca da fase acional encontram-se materializadas no comportamento dos indígenas e nas atitudes do Capitão, que não mediu esforços para auxiliar seu povo na construçáo de uma imagem positiva de si. Em vista disso, junto com os velhos da aldeia, ele passou a atuar como anjo protetor, colocando-se à disposição para narrar a saga Parkatêjê e elucidar dúvidas eventuais.

Como resultado, as páginas do livro Me ikwy tekjê $r i^{9}$ resguardam cultura, tradiçóes, conselhos, reflexóes e muitos outros ensinamentos às futuras geraçôes. Esse feito tornou-se motivo de orgulho, conforme sublinham as palavras de Takwỳiti: "quando eu pegar esse livro, vou dizer 'fui eu que escolhi essa letra da capa'. Tenho certeza que tem a minha mão nesse livro" (JÓPAIPARE, 2011b, p. 21).

No trabalho de elaboração da aludida obra, a participação nas oficinas foi intensa e envolvente. $\mathrm{O}$ objetivo capital consistiu em intensificar o sentimento de pertencimento entre os habitantes da aldeia, os quais demonstraram comportamento autônomo no desenrolar das açóes, tomando eles próprios importantes decisóes sobre a obra. Essa atitude deixou efeitos positivos, pois segundo eles, "aprendemos bastante nas oficinas que ocorreram durante a elaboração desse material. Todas as etapas do trabalho foram relevantes para nossa formação integral, com o envolvimento dos participantes, desde as entrevistas e transcrição dos textos, até a ilustraçáo do material" (JÔPAIPARE, 2011b, p. 27).

A fala dos indígenas exemplifica o que Dörnyei (2011, p. 214) denominou como "geração e implementação de subtarefas". Ao longo do trabalho, os indígenas foram impelidos a dar conta de outros subdesafios, que foram administrados com êxito e interpretados como significativos para mantê-los motivados a prosseguir. Em consequência, os Parkatêjê mostraram-se autoconfiantes e pro- 
puseram-se a caminhar além do objetivo inicial, aceitando também registrar sua história em vídeo.

No vídeo intitulado "Eu não posso morrer de graça", Krôhôkrenhữm e Japênprãmti relembram a história dos Parkatêjê, seus primeiros contatos com os kupẽ (não índios), em 1957, as guerras, as epidemias, as mortes etc. Em paralelo à narração da história, são filmados outros episódios, como o processo de organização do livro e suas atividades culturais, a exemplo das saídas para caçar, jogos de arco e flecha, corridas de tora, alimentação, artesanato, pintura corporal, cantos, entre outras. Essas açóes muito contribuíram para despertar na geração mais jovem um tipo de responsabilidade comprometida com a comunidade.

Por meio do vídeo, percebe-se que a iniciativa de realizar o sonho do Capitáo partiu da própria comunidade, sem nenhuma imposição do líder, que, em cena, não omite sua alegria de ver os jovens entusiasmados, reconhecendo-se como indígenas. Esse momento é ilustrado na fala de uma das mulheres: "estamos aqui para aprender a cantar, falar, chorar na nossa língua [...] é a nossa cultura que está em jogo [...] A gente tem que ter esperança que podemos resgatar porque o que será de nossos filhos [...] nossa cultura ainda não morreu!" (JÓPAIPARE, 2011a).

As gravaçóes destacam o episódio em que, embora sem conhecimento teórico, Krôhôkrenhữm coloca em prática uma estratégia bastante motivadora para reforçar o interesse pelo aprendizado da língua tradicional. Ele convida os jovens a visitar os Krahô ${ }^{10}$, encontro no qual Jarurêre, um dos jovens da comunidade Parkatêjê, revela sua admiração ao observar que os Krahô sabem falar sua língua nativa. $\mathrm{O}$ indígena chama a atençáo dos demais para o exemplo daquela comunidade e os incentiva a estendê-lo à sua aldeia.

A atitude de Jarurêre serviu para dinamizar açóes motivadoras no grupo. Com base em Dörnyei (2011), entende-se que a avaliação e a reflexão desse jovem acerca de estímulos provenientes do ambiente, acrescidas ao desenvolvimento de seu povo naquele momento, incentivaram a busca por novas estratégias centradas na execução da ação. Com efeito, na fase acional, influências como as apresentadas no referido encontro entram em cena para controlar e impulsionar a motivação, a fim de alcançar um resultado.

Ao finalizarem o desafio, os Parkatêjê avaliaram que "o trabalho foi difícil no momento da transcrição, de ouvir o gravador e repetir várias vezes, para entender" (JÔPAIPARE, 2011a, p. 188). Por outro lado, também o consideraram "fácil, porque o Capitão mesmo indicou o roteiro que queria seguir, mostrando como nós poderíamos fazer perguntas" (JÓPAIPARE, 2011b, p. 188). Com relação ao aprendizado geral, os resultados são de duas ordens:

Primeiramente, o resultado de aprendermos coisas que não conhecíamos, detalhes de nossas tradiçóes de que não estávamos mais cuidando e a que náo dávamos o valor devido. Em segundo 
lugar, a elaboração desse livro foi um ato de amor, no qual nos envolvemos de corpo e alma. Vivemos, na prática, o ensinamento de nosso chefe: não se deve trabalhar 'adoidado', de qualquer jeito. É preciso pensar, fazer esforço; é preciso empenhar-se, é preciso lutar e até mesmo sofrer, quando acreditamos em algo (JÓPAIPARE, 2011b, p. 29).

Com a conclusão de seu intento, Krôhôkrenhữm póe fim também ao que era seu maior medo: morrer sem deixar documentada a história de seu povo, ainda que minimamente. Como protagonista, ele se vê, agora, imortalizado em sua cultura. Certo de ter cumprido essa missão, deixa uma mensagem para sua comunidade: "vocês verão a minha sombra e poderão aprender” (JÓPAIPARE, 2011b).

\section{Considerações finais}

As discussóes abordadas no presente artigo evidenciam sinais de uma nova fase na educação brasileira, na qual as comunidades indígenas passam a ter autonomia para interferir nas decisóes referentes ao seu destino. A escola, antes cerceadora da liberdade do pensar, hoje representa o caminho por onde o indígena pode transitar no mundo dos não índios.

Ao que parece, todavia, mesmo após conquistas amparadas em lei, a EEI permanece em estágio incipiente no que diz respeito ao fortalecimento linguísticocultural dos povos em questáo. Isso foi comprovado, por exemplo, com a estimativa concernente ao número de falantes fluentes das aproximadamente 160 línguas nativas do Brasil e, em particular, com a realidade sociolinguística dos Parkatêjê. Diante disso, postula-se que o trabalho de elaboração de materiais didáticos inclusivos, bilíngues e interculturais apontados como estratégia de ensino não esteja considerando a etnografia das escolas às quais se destinam.

A experiência com os Parkatêjê é digna de reconhecimento por tê-los feito acreditar em sua capacidade de produzir conhecimento e de desenvolver atitudes autônomas. O projeto envolveu-os em aprendizagens significativas de diversas ordens, e despertou interesse, na equipe de produção, para futuras pesquisas sobre outros aspectos de sua tradição. A obra "feita por suas mãos" representa material importante para fins pedagógicos e poderá ser utilizada em situaçóes de educaçáo intercultural.

O exemplo desse povo constitui um passo decisivo para o fortalecimento de sua autonomia e a reafirmaçáo de sua identidade linguístico-cultural, além de favorecer reflexóes acerca da EEI. Assim, é importante divulgá-lo a outros povos que ainda não despertaram para reclamar o seu lugar como os cidadáos brasileiros que são e para exigir o reconhecimento de suas diferenças socioculturais. 


\section{Notas}

1 Quando havia cerca de 1 milhão de indígenas. Dizimados por doenças epidêmicas, fome e maus tratos, hoje estáo reduzidos a, aproximadamente, 800 mil, a maior parte concentrada nas regióes norte e nordeste, segundo informaçôes fornecidas em 2010 pelo Instituto Brasileiro de Geografia e Estatística (IBGE) (ANTUNES, 2011).

2 Termo utilizado pelos colonizadores para generalizar os povos indígenas e, portanto, ignorar as características culturais de cada etnia.

3 Faz parte da cultura indígena a utilização do termo "velho" para se referir aos índios da primeira geração. Eles são muito respeitados, pois representam a força da tradição indígena (SIMAS; PEREIRA, 2010).

4 Portaria Interministerial 559 (1991); LDB (Lei 9.394/96); Plano Nacional de Educação (PNE) (Lei 10.172/01); RCNEI (1998); Constituições estaduais; normas e diretrizes de Conselhos estaduais e municipais de educação (MONSERRAT, 2006).

5 Existem, no Brasil, comunidades indígenas, comunidades imigrantes (alemãs, italianas, japonesas, polonesas, ucranianas etc.), de brasileiros descendentes de imigrantes e de brasileiros não descendentes de imigrantes em regiôes de fronteira, além das comunidades de surdos (CAVALCANTI, 1999).

6 O cognome "Capitão" lhe foi atribuído pelos agentes do Serviço de Proteção aos Índios (SPI) (FERRAZ, 1984).

7 “Semente preta”. A aldeia tinha esse nome porque, nessa regiáo, havia grande quantidade de pamrehy, planta cujas sementes são utilizadas na confecção de adereços, maracás etc. e têm a cor preta.

8 Entre os quais: Lepoldina Araújo e Marília Ferreira, linguistas da Universidade Federal do Pará (UFPA); Vincent Carelli, antropólogo e fundador do Projeto Vídeo nas Aldeias; Antônio Venâncio, da Companhia Vale do Rio Doce (CVRD); e Guilherme Noronha, designer e fotógrafo.

9 "Isto pertence ao meu povo".

10 Assim como os Parkatêjê, os Krahô filiam-se ao complexo dialetal Timbira.

\section{Referências}

ANTUNES, A. Povos indígenas: quem são e o que reivindicam os índios do Brasil. Poli: Saúde, Educação, Trabalho, ano 3, n. 18, p. 4-13, jul./ago. 2011. Disponível em: http:// www.epsjv.fiocruz.br/sites/default/files/revista poli - 18.pdf. Acesso em: 15 set. 2012.

ARAÚJO, L.M.S. La escuela: instrumento de resistencia de los parkatêjê. In: GONZALBO, Aizpuru (Coord.). Educación rural e indígena en Iberoamérica. México: Universidad Nacional de Educación a Distancia, 1996.

Parkatêjề $\times$ português: caminhos de resistência. In: CONGRESSO INTERNACIONAL DA BRAZILIAN STUDIES ASSOCIATION, 9., 2008, Nova Orleans. Anais... Nova Orleans, Tulane University, 2008. Disponível em http://www. brasa.org. Acesso em: 10 set. 2012. 
BARBOT, M.-J.; CAMATARRI, G. Autonomie et apprentissage: l'innovation dans la formation. Paris: PUF, 1999.

BENSON, P. Teaching and researching: autonomy in language learning. Harlow: Pearson, 2001.

BOMFIM, A.B.; COSTA, V.F. Revitalização de língua indígena no sul da Bahia. In: ; __ (Orgs.). Revitalização de lingua indigena e educação escolar indígena inclusiva. Salvador: EGBA, 2014.

BRASIL. Ministério da Educação. Lei n. ${ }^{\circ}$ 9.394: Diretrizes e bases da educação nacional. Brasília: MEC, 1996.

. Ministério da Educação. Secretaria de Educação Básica. Ensino fundamental de 9 anos: orientações gerais. Brasília: MEC, 2004.

CAVALCANTI, M. Estudos sobre educação bilíngue e escolarização em contextos de minorias linguísticas no Brasil. Delta, v. 15, p. 385-417, 1999. Número especial.

COHN, C. A cultura nas escolas indígenas. In: CUNHA, M.C.; CESARINO, P.N. (Orgs.). Politicas culturais e povos indígenas. São Paulo: Cultura Acadêmica, 2014.

D’ANGELIS, W.R. Línguas indígenas no Brasil: urgência de açóes para que sobrevivam. In: BOMFIM, A.B.; COSTA, F.V. (Orgs.). Revitalização de língua indígena e educação escolar indigena inclusiva. Salvador: EGBA, 2014.

DANTAS, L.; MAGNO E SILVA, W. Motivação e autonomia para a formação de um novo professor. In: ASSIS, R. (Org.). Estudo da lingua portuguesa e de todas as linguas que fazem a nossa. Belém/PA: UNAMA, 2006. v. 6. p. 139-151.

DÖRNYEI, Z. Motivação em ação: buscando uma conceituação processual da motivação de alunos. In: BARCELOS, A.M. (Org.). Linguistica aplicada: reflexôes sobre ensino e aprendizagem de língua materna e língua estrangeira. Tradução de Walkyria Magno e Silva e André Monteiro Diniz. Campinas: Pontes, 2011. v. 13. p. 220-236. (Coleção: Novas Perspectivas em Linguística Aplicada).

FERRAZ, I. Os Parkatêjê das matas do Tocantins: a epopeia de um líder Timbira. 1984. 151 f. Dissertação (Mestrado em Antropologia) - Universidade de São Paulo, São Paulo.

FERREIRA, M.N. Estudo morfossintático da língua parkatêjê. 2003. Tese (Doutorado em Linguística) - Universidade Estadual de Campinas, Campinas.

FREIRE, J.R.B. A demarcação das línguas indígenas no Brasil. In: CUNHA, M.C.; CESARINO, P.N. Politicas culturais e povos indígenas. São Paulo: Cultura Acadêmica, 2014.

FREIRE, P. Pedagogia da autonomia: saberes necessários à prática educativa. São Paulo: Paz e Terra, 2011.

JÓPAIPARE, T.K. Eu não posso morrer de graça. Direção: Vicent Carelli. Produção: Vídeo nas Aldeias. Marabá: Gknoronha, 2011a. 1 DVD (53 min.), color. . Me ikwy tekjê ri: isto pertence ao meu povo. Marabá: Gknoronha, 2011a.

LARAIA, R.B.; DA MATTA, R. Índios e castanheiros: a empresa extrativa e os índios no Médio Tocantins. 2. ed. Rio de Janeiro: Paz e Terra, 1978. v. 35. (Coleção Estudos Brasileiros). 
MAHER, T.M. A formação de professores indígenas: uma discussão introdutória. In: GRUPIONI, L.D.B. (Org.). Formação de professores indígenas: repensando trajetórias. Brasília: MEC, 2006. p. 11-38.

MONSERRAT, R.M.F. Política e planejamento linguístico nas sociedades indígenas do Brasil hoje: o espaço e o futuro das línguas indígenas. In: GRUPIONI, L.D.B. (Org.). Formação de professores indígenas: repensando trajetórias. Brasília: MEC, 2006. p. 131-154.

PAIVA, V.L.M.O. O modelo fractal de aquisição de línguas. In: BRUNO, F.C. (Org.). Ensinoaprendizagem de linguas estrangeiras: reflexão e prática. São Carlos: Claraluz, 2005. p. 23-35.

; VIEIRA, L.I.C. A formação do professor e a autonomia na aprendizagem de língua inglesa no ensino básico. 2005. Disponível em: http://www.veramenezes.com/ enpuli2005.htm. Acesso em: 12 abr. 2012.

RODRIGUES, A.D. Linguas brasileiras: para o conhecimento das línguas indígenas. São Paulo: Loyola, 1986.

SANTOS, J.L. O que é cultura. 14. ed. São Paulo: Brasiliense, 1994. (Coleção Primeiros Passos).

SILVA, R.G. Educação escolar na fronteira do Brasil entre os Karipuna e Galibi-Marworno: da assimilação à autonomia. In: SIMPÓSIO NACIONAL DE HISTÓRIA, 26., 2011, São Paulo. Anais... São Paulo: ANPUH, 2011.

SIMAS, H.C.P.; PEREIRA, C.M. Desafios da educação escolar indígena. Escrita, Rio de Janeiro, n. 11, 2010. Disponível em: http://www.maxwell.vrac.puc-rio.br/16373/16373.PDF. Acesso em: 28 set. 2011.

Recebido em 28 de outubro de 2013.

Aprovado em 27 de setembro de 2016. 